\title{
THE STRUCTURE AND SYSTEMATIC POSITION OF STRONGYLUS POLYGYRUS.
}

\author{
By C. L. BOULENGER, M.A., D.Sc. \\ (From the Zoological Department, University of Birmingham.)
}

(With 4 Text-figures.)

DuJARDIN (1845) was the first to give a satisfactory account of the small Strongylid worms inhabiting the intestinal tract of field-mice and voles. His descriptions of the various species were careful and for the most part accurate, they were, unfortunately, not accompanied by figures, and incomplete in that the characters of the bursal rays of the males were not given, an omission which has led to considerable confusion, since the modern classification of the Trichostrongylidae is based largely on the structure of the male bursa.

Of the four worms described by Dujardin, Strongylus costellatus has been taken as the type of the genus Heligmosomum Railliet and Henry (1909), to which genus his other species $S$. minutus, S. laevis and $S$. polygyrus were also assigned. On the authority of Travassos (1914) S. polygyrus has since been removed to his genus Viannaia by Hall (1916) who, however, remarks that the available descriptions are not sufficiently detailed to warrant the change.

I have recently been fortunate in obtaining a number of small Strongylids from the intestine of Microtus (Arvicola) agrestis L. from the neighbourhood of Birmingham, which I am convinced belong to the same species as that described by Dujardin as $S$. polygyrus, their study has enabled me to clear up a number of misconceptions with regard to this form.

Von Linstow (1878, 1879 and 1882) is the only authority since Dujardin who has attempted to reinvestigate the species; his account contains descriptions and figures of the male bursa, but in certain important characters the worm studied by him seems to deviate so much from the original specific diagnosis that Hall (1916) felt justified in concluding that a different form had been dealt with by the German helminthologist, and in removing it to a new genus Heligmosomoides under the designation $H$. linstowi Hall. Travassos (1921) accepts Hall's conclusions and in his recent monograph on the T'richostrongylidae we find $S$. polygyrus Dujardin listed as Viannaia polygyra and S. polygyrus von Linstow as Heligmosomoides linstowi. 
My investigations of the new material have led me to a quite opposite conclusion, and I am convinced that Dujardin and von Linstow have dealt with the same species. The specimens before me agree in all important characters with $S$. polygyrus as described by the French author; at the same time it is quite easy to reconcile my account of the male bursa with von Linstow's description and figures. The confusion has been due largely to the latter's mistake with regard to the position of the vulva of the female, but partly also to a misunderstanding of Dujardin's original description by some recent authors.

Dujardin's specific diagnosis of $S$. polygyrus clearly shows that one of the important characters of the species is the shape of the female tail, the latter being narrow, conical, truncated posteriorly and terminated by a slender, transparent spike $0.02 \mathrm{~mm}$. in length; the anus is given as $0.075 \mathrm{~mm}$. from the posterior extremity. The shape of the tail is therefore very similar to that found in species of the genus Nematodirus.

Hall (1916) has evidently misunderstood Dujardin's account, in his diagnosis he gives "Tail $20 \mu$ long, thin, conical, diaphanous, truncated, and terminating abruptly in a narrow point. Anus $75 \mu$ from the tip of the tail," further commenting on the fact that Dujardin evidently does not regard the length of the tail and the distance from the anus to the tip of the tail as the same thing. Dujardin's actual words are "queue amincie, conique, tronquée, et terminée brusquement par une pointe grêle, diaphane, longue de $0 \mathrm{~mm} ., 02$; -anus à $0 \mathrm{~mm}$., 075 de l'extrémité." The measurement $0.02 \mathrm{~mm}$. here clearly refers to the length of the terminal spike, not to that of the tail.

It is evident therefore that in the shape of the female tail, with its truncate extremity and terminal spike, we have an important character which distinguishes $S$. polygyrus from $S$. costellatus, the type species of the genus Heligmosomum. The form examined by von Linstow clearly possessed this character, the anus being described as $0.098 \mathrm{~mm}$. from the end of the tail and definite reference made to a slender, terminal spike, $0.016 \mathrm{~mm}$. long.

Von Linstow described the vulva as $0.24 \mathrm{~mm}$. from the head end, one of the chief characters used by Hall and Travassos in separating $S$. polygyrus v. Linst. from S. polygyrus Duj.; this statement I think, however, should be regarded as a clerical error, Kopfende having been accidentally substituted for Schwanzende. The distance $0.24 \mathrm{~mm}$. from the head end would place the vulva anterior to the termination of the oesophagus, an almost impossible situation in this group of Nematodes; von Linstow's description of the ovejector (1882) is, moreover, incompatible with such a forward position for the vulva.

The specimens obtained by me from the Birmingham voles agree with those described by Dujardin and von Linstow in so far as the shape of the tail and the position of the anus are concerned. The vulva was found to be situated $0 \cdot 24-0.35 \mathrm{~mm}$. from the posterior extremity.

Dujardin's account contains little useful information with regard to the 
male organs, the spicules are, however, given as $0.58 \mathrm{~mm}$. long, this measurement agreeing well with von Linstow's $(0.54 \mathrm{~mm}$.) and that observed by me in the new material $(0 \cdot 5-0.58 \mathrm{~mm}$.).

Von Linstow's description and figures of the male bursa have given rise to much discussion; according to his account the bursa of $S$. polygyrus has no separate dorsal lobe and no median dorsal ray, the latter being replaced by two rays with separate origins; between these and behind the cloaca are shown seven pairs of small ray-like structures ending in papillae. The bursal characters as figured by von Linstow differ so much from those of other species now assigned to the genera Heligmosomum and Viannaia as to justify Hall's transference of the worm to a new genus Heligmosomoides.

Travassos (1921) accepts the systematic position assigned to the species by Hall, but adopts a somewhat different interpretation of von Linstow's figures of the bursa; he prefers to regard the two dorsal rays as representing the externo-dorsal rays of other species, and the true dorsal rays as being replaced by the seven pairs of small post-cloacal rays.

My material has shown that Travassos' interpretation is the more correct. In the Birmingham specimens the male bursae bear a striking resemblance, both in shape and in the general arrangement of the ventral and lateral rays, to those figured by von Linstow. When completely spread out and viewed from the dorsal or ventral aspect (text-fig. 3 ) the bursa is seen to be of considerable width with an almost straight dorsal margin, without a separate dorsal lobe or marked median incision. There are two long, slender externo-dorsal rays with separate origins, and, between them, a very small median dorsal ray branching dichotomously into four delicate branches. A genital cone is well developed, bearing one or two pairs of small, but highly refractile papillae on each side of the cloaca.

In an incompletely extended bursa, as shown in text-fig. 4, the two externodorsal rays appear much closer together and the genital cone covers and hides the greater part of the dorsal ray, revealing only the tips of the four branches which, together with the cloacal papillae, give the appearance of a series of small rays in the neighbourhood of the genital opening.

The peculiarities of von Linstow's figures of the bursa of $S$. polygyrus are thus readily explained; comparison of these figures (1878, Fig. 21 and 1879, Fig. 26) with my own (text-figs. 3,4 ) will show conclusively that the form described here is specifically identical with that studied by the German authority.

The facts stated above make it clear that there is no justification for the separation of $S$. polygyrus Duj. and $S$. polygyrus v. Linst. It is evident from the structure of the female tail and from the peculiarities of the male bursa that the species cannot be referred to either of the genera Viannaia or Heligmosomum; Hall's genus Heligmosomoides must therefore be retained, the worm, however, figuring as $H$. polygyrus (Duj.) instead of H. linstowi Hall. 
A revised diagnosis of the genus Heligmosomoides is given below, together with a new specific diagnosis of $H$. polygyrus based on the material before me:

\title{
HELIGMOSOMOIDES Hall, 1916.
}

Generic diagnosis. Heligmosominae: Body commonly coiled in a spiral, with transverse and longitudinal striations. Male with long, filiform spicules. Bursa without separate dorsal lobe or middorsal incision. Dorsal ray very short with four small branches. The externo-dorsal rays are long and slender, with separate origins. The lateral rays arise from a common trunk and are divergent. Ventro-ventral and latero-ventral rays divergent with a common origin. Prebursal papillae long. Female with a truncated posterior extremity bearing a slender caudal spike. Vulva situated posteriorly.

Type species. H. polygyrus (Dujardin, 1845).

\section{Heligmosomoides polygyrus (Dujardin, 1845).}

\author{
SYNonys: Strongylus polygyrus Dujardin, 1845. \\ , von Linstow, 1878. \\ Heligmosomum polygyrum Railliet and Henry, 1909. \\ Viamaia polygyra Hall, 1916. \\ Heligmosomoides linstowi Hall, 1916.
}

Small worms, reddish in colour when alive, and usually coiled in a spiral.

The head, $0.04-0.05 \mathrm{~mm}$. wide, is provided with a cuticular expansion, usually asymetrically developed and with conspicuous transverse striations (text-fig. 2). Head papillae appear to be present, but their number and arrangement could not be definitely ascertained.

The cuticle of the body is striated both longitudinally and transversely, there are, moreover, 18-20 longitudinal crests. The transverse striations are very fine and most apparent along these crests and in the neighbourhood of the vulva of the female.

The oesophagus is short, $0.48-0.6 \mathrm{~mm}$. in length. There is a small buccal cavity with chitinous walls.

Male: $4.5-5.5 \mathrm{~mm}$. long, with a maximum thickness of $0.07-0.09 \mathrm{~mm}$. in the posterior part of the body.

The bursa has a length of $0 \cdot 17-0.18 \mathrm{~mm}$. and a breadth of $0.3-0.33 \mathrm{~mm}$. The dorsal edge of the bursa is almost straight (text-fig. 3), there is no separate dorsal lobe or median dorsal incision separating the lateral lobes.

The dorsal ray is slender and very short, branching dichotomously into four small rays, the total length of dorsal ray and its branches measures $0.025-0.035 \mathrm{~mm}$. In the neighbourhood of the dorsal ray the bursa is frequently transversely folded, so as to give the appearance of an accessory bursal membrane. The externo-dorsal rays are long and slender, they have 
separate origins and extend almost to the margin of the bursa. The lateral rays arise from a common trunk and are divergent; the postero-lateral ray is

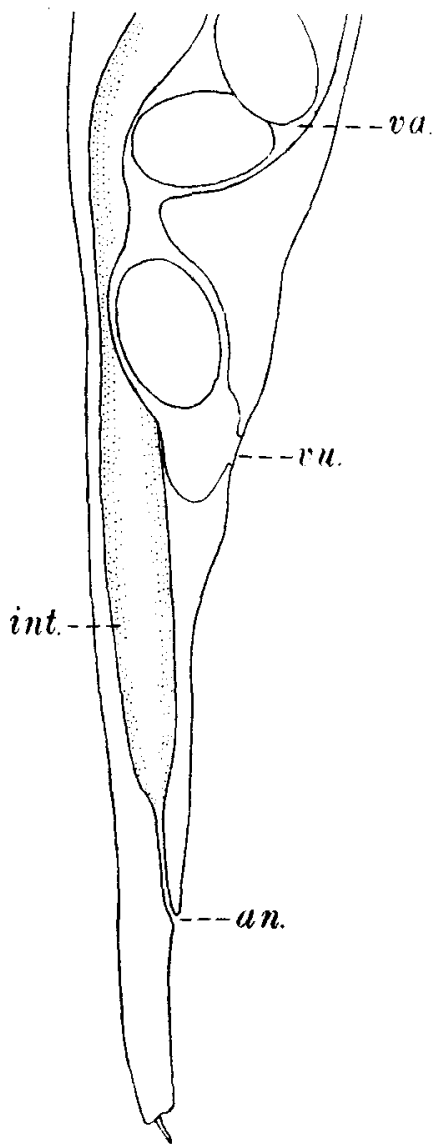

Fig. 1. Helignosomoides polygyrus. Posterior extremity of female, lateral view. $\times$ about 220 .

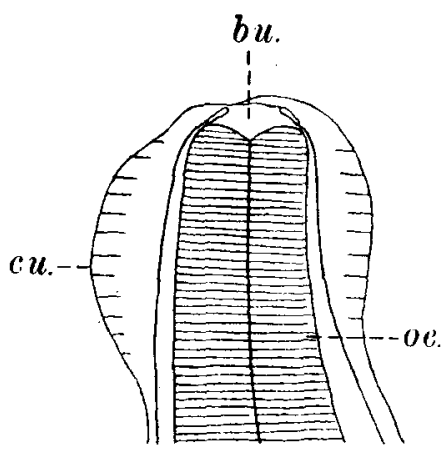

Fig. 2. Heligmosomoides polygyrus. Head, with cuticular expansion. $\times$ about 650 .

only slightly thicker than the externo-dorsal and runs almost parallel with it, the medio-lateral and externo-lateral rays are considerably thicker than the 


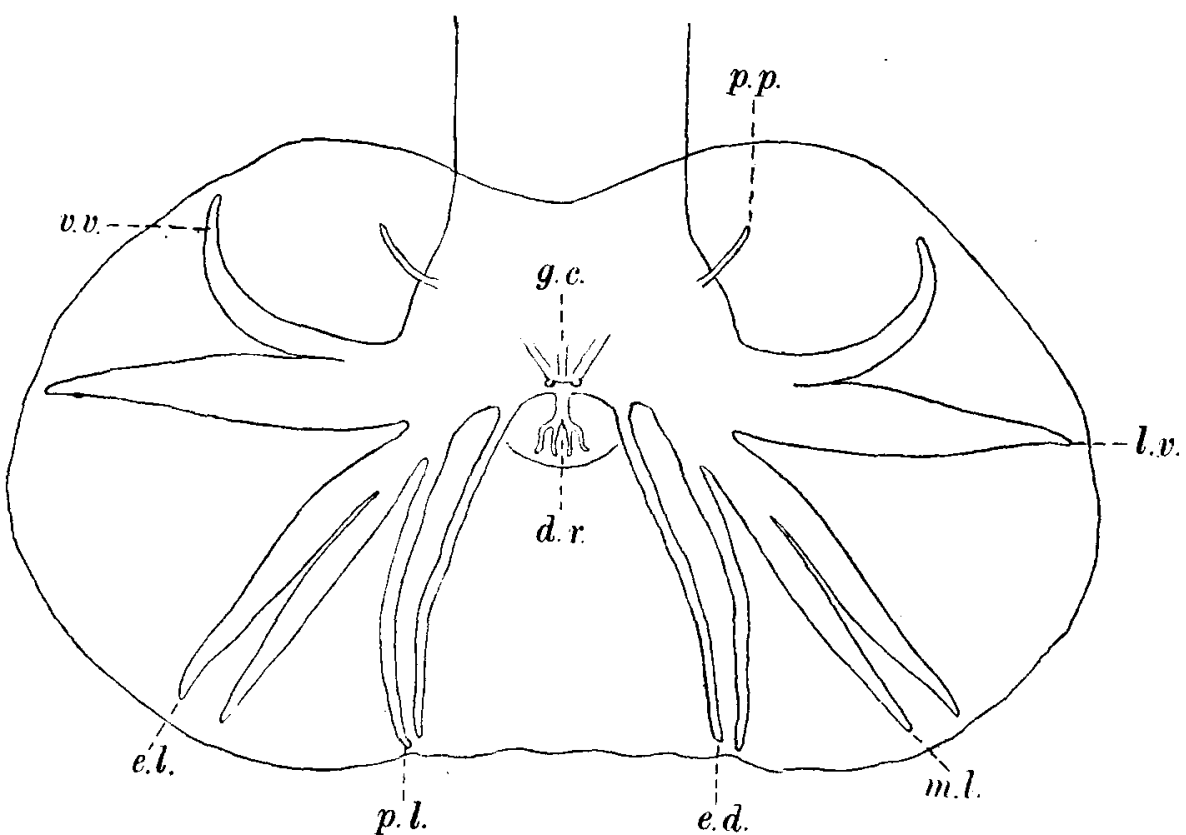

Fig. 3. Heligmosomoides polygyrus. Male bursa, ventral view. $\times$ about 350 .

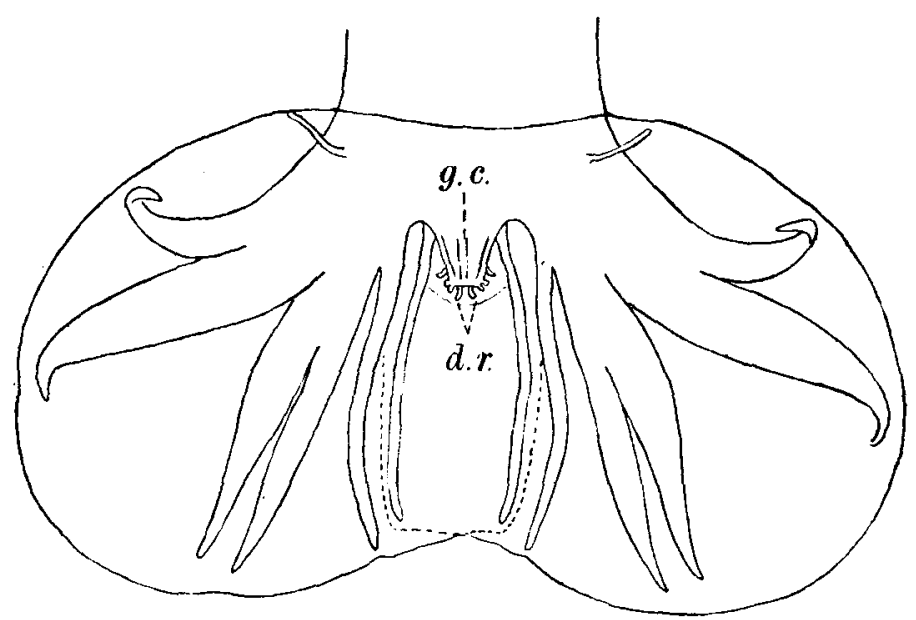

Fig. 4. Heligmosomoides polygyrus. Male bursa, incompletely spread out; the dorsal region is folded longitudinally so as to approximate the externo-dorsal rays, the genital cone covers the greater part of the dorsal ray. $x$ about 350 .

\section{EXPLANATION OF LETTERING.}

$a n$., anus; $b u$., buccal eavity; $c u$., cuticular expansion of head; d.r., dorsal ray; e.d., externo. dorsal ray; e.l., externo-lateral ray; g.c., genital cone; int., intestine; l.v., latero-ventral ray; $m . l$. , medio-lateral ray; oe., oesophagus; $p . l$. , postero-lateral ray; $p . p$. , prebursal papilla; $v a$. , vagina; $\because . v$., ventro-ventral ray; $v^{\prime} u$, vulva. 
postero-lateral. The ventral rays arise from a common trunk and are markedly divergent; the latero-ventral is very thick, being quite twice as broad as the other bursal rays, the tip of the ventro-ventral ray is directed towards the anterior border of the bursa. Prebursal papillae are well developed and are long and slender.

The simple, filiform spicules are $0.5-0.58 \mathrm{~mm}$. long, their distal portions are united. No gubernaculum could be traced.

Female : $6 \cdot 2-10 \mathrm{~mm}$. long. The greatest width of the body is in the posterior third, where it measures $0.09-0.12 \mathrm{~mm}$. ; the width in the middle of the body is $0.06-0.08 \mathrm{~mm}$.

The anus is $0 \cdot 067-0 \cdot 1 \mathrm{~mm}$. from the posterior extremity; the tail is conical, truncated posteriorly, and bearing a slender, pointed terminal spike which measures 0.012-0.018 mm. in length (text-fig. 1).

The vulva is a conspicuous opening, situated $0 \cdot 24-0.35 \mathrm{~mm}$. from the tip of the tail. The female organs are single; the ovejector is well developed and similar in shape to that described by von Linstow (1882), the combined length of the vagina and ovejector (exclusive of anterior nonmuscular portion) is $0.45-0.55 \mathrm{~mm}$.

The eggs are $0.62-0.78 \mathrm{~mm}$. long by $0.035-0.045 \mathrm{~mm}$. wide, they are in the morula stage when laid.

The systematic position of $S$. laevis Dujardin remains to be considered. Stossich (1899) has suggested that this is a synonym of $S$. polygyrus. According to Dujardin the two worms are very closely allied and only to be distinguished with difficulty. He specially notes that the caudal extremity of the female is similar in the two species, $S$. laevis also having the extremity truncate and bearing a terminal spike. In the absence of any description of the male bursa we have only the female characters to help us in assigning a position to this worm among the genera of Heligmosominae; these strongly suggest that $S$. laevis should be placed alongside $S$. polygyrus in the genus Heligmosomoides.

Seurat (1915) has published a description of a worm from Dipodillus campestris in Algeria which he considers to be $S$. laevis; his account shows that in this form the bursa is divided into distinct dorsal and lateral lobes, and possesses a long dorsal ray, the branches of which extend to the bursal margin; the female tail is conical with a pointed termination. If these characters are correctly interpreted, I think there can be little doubt that Dujardin's species was not dealt with.

\section{REFERENCES.}

DuJARDin, F. (1845). Histoire naturelle des Helminthes ou Vers Intestinaux. Paris.

Hall, M. C. (1916). Nematode Parasites of Mammals of the Orders Rodentia, Lagomorpha and Hyracoidea. Proc. U.S. Nat. Mus. L. 1-258.

Linstow, O. von (1878). Neue Beobachtungen an Helminthen. Arch. f. Naturg., Berlin, XLIV. 218-244.

(1879). Helminthologische Studien. Arch. f. Naturg. XLv. 167-188. 


\section{L. Boulengher}

Linstow, O. von (1882). Helminthologische Studien. Arch. f. Naturg. xLvir. 1-25.

Railliet, A. and Henry, A. (1909). Sur la Classification des Strongylidae. I. Metastrongylinae. C. r. Soc. de Biol., Paris, LXvi. 85-88.

Sevrat, L. G. (1915). Sur les Conditions de la Ponte du Strongle Lisse. Bull. Sci. France et Belgique, XLviII. 171-177.

Stossich, M. (1899). Strongylidae. Lavoro monografico. Boll. Soc. adriat. di sci. nat., Trieste, xIx. 55-152.

Travassos, L. (1914). Tricostrongylideos brasileiros (3. nota previa). Brazil med. xxxiv. Sept. 326.

(1921). Contribuções para o conhecimento da fauna helmintolojica brasileira. XIII. Ensaio monografico da familia Trichostrongylidae Leiper, I909. Mem. Inst. Oswaldo Cruz, Rio de Janeiro, xIII. 1-135. 